\title{
EHMTI-0321. Restricted diffusion in painful ophthalmoplegia
}

\author{
$\mathrm{JH} \mathrm{Choi}{ }^{*}$, IS Moon ${ }^{2}, \mathrm{SH} \mathrm{Kim}{ }^{3}, \mathrm{KD} \mathrm{Choi}^{4}$ \\ From 4th European Headache and Migraine Trust International Congress: EHMTIC 2014 \\ Copenhagen, Denmark. 18-21 September 2014
}

\section{Introduction and aims}

Superior ophthalmic vein (SOV) thrombosis is a rare disease entity characterized by rapidly progressive orbital symptoms, including periorbital edema, chemosis, proptosis and painful ophthalmoplegia. Since diagnostic delays represent a life-threatening danger, early recognition of disease is important for effective treatment and good prognosis. We report a patient with SOV thrombosis showing restricted diffusion within the vein on diffusion-weighted images (DWI) which may be helpful in the diagnosis of SOV thrombosis.

\section{Methods and results}

A 53-years-old man presented with headache and left eye swelling for 6 days. Neurological examination revealed proptosis, eyelid edema, and depression paresis in the left eye. Left pupil was dilated and sluggishly reacting to light. Orbit MRI showed diffuse enhancement in the left retro-orbital and periorbital area, and an intraluminal filling defect within the left SOV. DWI disclosed high signal intensity in the left SOV, confirmed on apparent diffusion coefficient (ADC) map by the low signal intensity in the corresponding region. These restricted diffusions were attributed to the presence of thrombus within the left SOV. Based on clinical symptoms and MRI findings, a diagnosis of SOV thrombosis caused by orbital cellulitis was made, and intravenous broad-spectrum antibiotics infusion was initiated. Over the next 7 days he showed a marked improvement of periorbital swelling, and limitation of the eye movement gradually improved.

\section{Conclusions}

DWI may provide a clue for the presence of intravascular clots according to the stage of thrombus

${ }^{1}$ Neurology, Pusan National University Yangsan Hospital, Yangsan, Korea Full list of author information is available at the end of the article formation which can help the diagnostic process in SOV thrombosis.

No conflict of interest.

\section{Authors' details}

'Neurology, Pusan National University Yangsan Hospital, Yangsan, Korea. ${ }^{2}$ Neurology, Daedong Hospital, Busan, Korea. ${ }^{3}$ Neurology, Dong-A University Hospital, Busan, Korea. ${ }^{4}$ Neurology, Pusan National University Hospital, Busan, Korea.

Published: 18 September 2014

doi:10.1186/1129-2377-15-S1-D8

Cite this article as: Choi et al: EHMTI-0321. Restricted diffusion in painful ophthalmoplegia. The Journal of Headache and Pain 201415 (Suppl 1):D8.

\section{SpringerOpen ${ }^{\odot}$}

C 2014 Choi et al; licensee Springer. This is an Open Access article distributed under the terms of the Creative Commons Attribution License (http://creativecommons.org/licenses/by/2.0), which permits unrestricted use, distribution, and reproduction in any medium, provided the original work is properly cited.
Submit your manuscript to a SpringerOpen ${ }^{\circ}$ journal and benefit from:

- Convenient online submission

- Rigorous peer review

- Immediate publication on acceptance

- Open access: articles freely available online

- High visibility within the field

Retaining the copyright to your article

Submit your next manuscript at $>$ springeropen.com 